\title{
Arabidopsis thaliana Metabolites Secreted by Roots during Plant Growth in Phosphorus-Limiting Conditions
}

\author{
Liliia R. Abdulkina ${ }^{{ }^{*}}$, Inna A. Agabekian ${ }^{*}$, Inna B. Chastukhina ${ }^{{ }^{*}}$, Lia R. Valeeva1, \\ Yulia D. Romanova1, Irina V. Khilyas', Margarita R. Sharipova', Eugene V. Shakirov ${ }^{1,2 \#}$ \\ ${ }^{1}$ Institute of Fundamental Medicine and Biology, Kazan Federal University, Kazan, Russia \\ ${ }^{2}$ Department of Integrative Biology, University of Texas at Austin, Austin, USA \\ Email: nigmatullinalili@mail.ru, "evshakirov@kpfu.ru
}

How to cite this paper: Abdulkina, L.R., Agabekian, I.A., Chastukhina, I.B., Valeeva, L.R., Romanova, Y.D., Khilyas, I.V., Sharipova, M.R. and Shakirov, E.V. (2019) Arabidopsis thaliana Metabolites Secreted by Roots during Plant Growth in Phosphorus-Limiting Conditions. American Journal of Plant Sciences, 10, 987-1001.

https://doi.org/10.4236/ajps.2019.106071

Received: May 17, 2019

Accepted: June 18, 2019

Published: June 21, 2019

Copyright $\odot 2019$ by author(s) and Scientific Research Publishing Inc. This work is licensed under the Creative Commons Attribution International License (CC BY 4.0).

http://creativecommons.org/licenses/by/4.0/

\begin{abstract}
Phosphorus is one of the most important nutrients required for plant growth and development. While substantial amounts of total phosphorus are present in many soil types, plants are unable to utilize some organic phosphorus sources. The main goal of this study was to characterize the spectrum of secreted plant proteins, organic acids and other metabolites that can potentially contribute to utilization of various phosphorus compounds. Our data indicate that the composition of extracellular proteins secreted by plant roots varies depending on the specific source of $\mathrm{P}$ in the growth medium. Furthermore, some root-secreted metabolites, such as citrate, appear to be specific to a subset of ecotypes, while tartrate, succinate and oxalate are secreted by a number of $A$. thaliana ecotypes. We observed secretion of phenolic compounds, such as tannins, and deoxycytidine derivatives. Taken together, while no single secreted polypeptide, organic acid or secondary metabolite can be pinpointed as specific to plant growth in particular phosphorus conditions, our data indicate that $A$. thaliana ecotypes differ in their physiological responses to the source of phosphorus in the growth medium. Overall, these results suggest that physiological changes in plant responses to nutrient limitation are modulated by interactions between soil phosphorus source and the specific genotype of Arabidopsis plants.
\end{abstract}

\section{Keywords}

Natural Variation, Ecotype, Root Exudates, P Deficiency, Secretion

${ }^{\star}$ These authors contributed equally to this work. 


\section{Introduction}

Phosphorus is one of the most important inorganic nutrients necessary for plant growth, development and physiology. While many soil types harbor substantial amounts of phosphorus-containing molecules, many of these compounds are characterized by low solubility or undergo rapid conversion to insoluble forms [1]. While common agricultural practices routinely rely on the addition of large amounts of phosphate fertilizers, this approach is not sustainable long-term, as it leads to irreversible depletion of non-renewable rock phosphate deposits and has a negative environmental impact due to phosphorus-associated pollution and eutrophication. Thus, an important aspect of modern plant science is to improve agricultural productivity in an environmentally friendly and cost-effective fashion, especially when plants are grown on phosphorus-deficient soils. Such agricultural approaches may include strategies to increase bioavailability of insoluble forms of soil phosphorus. Towards this goal, understanding mechanisms of how plants acquire and respond to various forms of phosphorus from soils may prove to be particularly important.

Plants growing in conditions of phosphorus deficiency can adjust their physiology to utilize alternative sources of phosphorus, including those that are hard to acquire [2]. Such physiological response includes changes in root morphology (inhibition of apical meristem growth and development of additional lateral roots and root hairs), an increase in the expression levels of phosphate transport genes, and induction and secretion of phosphatases into the rhizosphere. Secreted phosphatases have been found in many plants, including Lupinus albus [3], Solanum lycopersicum [4], Phaseolus vulgaris [5], Nicotiana tabacum [6] and Arabidopsis thaliana [7]. Indeed, secretion of acid phosphatases appears to improve hydrolysis of phosphorus-containing compounds in the rhizosphere [7].

In many agricultural soil types, organic phosphorus-containing compounds make up to $30 \%-80 \%$ of total soil phosphorus [8] [9]. The effect of various types of secreted phosphatases on plant growth has been studied in experiments with transgenic $A$. thaliana and Glycine max plants. Specifically, improved growth was observed for plants expressing secreted phytases or phosphatases when they were grown on synthetic medium containing phytate as the sole source of phosphorus [10] [11] [12] [13]. Furthermore, some transgenic plants expressing extracellular phytases also acquired the ability to grow on natural soils with a high phytate content [14] [15]. Despite these technological advances, alternative routes to improving plant phosphorus metabolism are also being developed, including strategies to engineer better utilization of internal phosphorus reserves of plants.

A. thaliana is a common model organism often used for natural variation studies, with many locally adapted populations (ecotypes or accessions) that are broadly distributed throughout the northern hemisphere with a surprisingly wide range of diversification in morphological and physiological traits. In addi- 
tion, as a model organism, $A$. thaliana can be grown on Petri dishes with synthetic medium, allowing a detailed molecular analysis of its response to growth on various sources of phosphorus.

Here we investigated the physiological responses of several Arabidopsis ecotypes (Col-0, Hi-0, Mt-0, Sf-2) grown under conditions of phosphorus deficiency or on various sources of phosphorus, such as $\mathrm{Na}_{2} \mathrm{HPO}_{4}$ (inorganic phosphate), ATP (adenosine-3-phosphate) and phytate (myo-insitol hexakisphosphate sodium salt, IHP). Using a number of different biochemical approaches, we assessed the composition of secondary metabolites secreted by Arabidopsis roots in response to environments with different sources of phosphorus. Our results indicate that each $A$. thaliana ecotype differs in its responses to changes in phosphorus sources. Furthermore, root-secreted metabolites also appear to vary depending on the specific ecotype and the source of phosphorus in the medium.

\section{Materials and Methods}

\subsection{Plant Growth Conditions}

Seeds of Arabidopsis thaliana ecotypes Col-0, Hi-0, Mt-0 and Sf-2 (ABRC stock numbers CS6673, CS6736, CS1380 and CS6857, respectively) were germinated under sterile conditions on MS medium in Petri dishes [16] under a long-day regime ( 16 hours of light $/ 8$ hours of dark) and $60 \%$ humidity at $22^{\circ} \mathrm{C}$. After 5 days of growth on MS medium, seedlings were transferred into hydroponic system with standard mineral growth medium [17] supplied with $\mathrm{Na}_{2} \mathrm{HPO}_{4}(800$ $\left.\mu \mathrm{M} \mathrm{Na} \mathrm{HPO}_{4}\right)$, ATP $(89 \mu \mathrm{M}$, AppliChem) or IHP (133 $\mu \mathrm{M}$ Na-IHP, SigmaAldrich) as a sole source of phosphorus or grown with no added phosphorus source (No-P control). All experiments were conducted with three biological replicates (three hydroponic containers for each ecotype and growth condition).

\subsection{Extracellular Protein and Peptide Analysis}

After 21 day of growth on hydroponics, plants were carefully transferred into 50 $\mathrm{ml}$ of fresh standard mineral medium supplied with different $\mathrm{P}$ sources for 3 hours. Plant growth media were then concentrated at $4^{\circ} \mathrm{C}$ using ultrafiltration membranes Amicon Ultra-15 3K (3 kDa exclusion limit) [18]. Peptides and polypeptides excreted by $A$. thaliana roots were passed through Supelco Discovery DSC-18 solid phase extraction C18 cartridges (Supelco, PA, USA). After extraction, $\mathrm{C} 18$ cartridges were rinsed twice with deionized water, and polypeptide elution was performed with $100 \%$ methanol. Residual peptides were then eluted with $80 \%$ acetonitrile. To analyze metabolites, growth medium was concentrated and evaporated on a rotary vacuum evaporator Concentrator plus/Vacufuge plus (Eppendorf, Hamburg, Germany) at $200 \mathrm{rpm}$ at room temperature.

UHPLC-ESI-Q-TOF-MS/MS analyses were performed using a Dionex UltiMate 3000 UHPLC connected to a Zorbax Eclipse Plus C-18 column $(2.1 \times 100$ $\mathrm{mm}, 1.8 \mu \mathrm{m}$ ) coupled to a Bruker MaXis IMPACT mass spectrometer. Mobile phase consisted of water/acetonitrile/formic acid (phase A was $94.9 \%$ water/5\% 
acetonitrile/0.1\% formic acid; phase B was $94.9 \%$ acetonitrile $/ 5 \%$ water $/ 0.1 \%$ formic acid) at a flow rate of $0.4 \mathrm{~mL} / \mathrm{min}$ [19]. The mobile phase gradient was increased from $0 \%$ to $2 \%$ (vol/vol) for $1 \mathrm{~min}$, then from $2 \%$ to $95 \%$ (vol/vol) during $5 \mathrm{~min}$, maintained at $95 \%$ for $1 \mathrm{~min}$, then decreased to $2 \%$ (vol/vol) of acetonitrile for $1 \mathrm{~min}$ until the next injection. Volume of injected sample was $10 \mu \mathrm{L}$.

\subsection{Organic Acids Analysis}

To study organic acids secreted by $A$. thaliana, roots were washed in Milli-Q water and placed in a new volume of MQ water for 8 hours. Identification of organic acids was performed on an Acclaim ${ }^{\circledast}$ Organic Acid OA C18 reverse-phase column $(3 \mu \mathrm{m}, 3.0 \times 150 \mathrm{~mm})$ using a UltiMate 3000 UHPLC system (Thermo Scientific, Dionex, USA) as described previously [20]. Separation of organic acids was carried out after their elution with $0.1 \mathrm{M}$ phosphate buffer ( $\mathrm{pH} 2.7$ ) at flow rate $0.5 \mathrm{~mL} / \mathrm{min}$. Elution of organic acids was monitored at $220 \mathrm{~nm}$. Organic acid standards (succinic, propionic, fumaric, butyric, DL-tartaric, oxalic and citric acids) were purchased from Applichem (HPLC quality).

\section{Results}

\subsection{Analysis of Proteins Secreted by A. thaliana Roots Grown on Media with Different Sources of Phosphorus}

A. thaliana secretes a number of extracellular proteins under normal and phosphorus-deficient growth conditions [21]. To study protein secretion by the roots of plants grown in conditions of phosphorus deficiency, we initially chose the Mt-0 ecotype of $A$. thaliana. This ecotype is specific to the nutrient-poor and sandy soils on the southern coast of the Mediterranean Sea in the dry subtropical climate of Libya, and we hypothesized that it may have certain physiological adaptations that can make it a good model system for our studies. Plants were grown in two types of conditions: a control environment with inorganic phosphorus $\left(\mathrm{Pi}, \mathrm{Na}_{2} \mathrm{HPO}_{4}\right.$ ) and phytate (IHP, an organic phosphorus compound that most plants are unable to utilize).

We performed methanol extraction of secreted proteins from plants grown in both conditions (Figure 1). We found only one common protein secreted by plant roots grown in both phosphorus-rich (Pi) and phosphorus-deficient (IHP) media. The identified At5g13610 gene product harbors the DUF155 domain involved in abscisic acid-activated and mitochondria-nucleus signaling pathways (Table 1). In the Pi medium, Mt-0 ecotype also secretes an oxidase (At1g03400 gene product) involved in ethylene biosynthesis, an auxin-responsive protein (At5g66260 gene product) and a Type IV inositol polyphosphate phosphatidylinositol 5-phosphatase 9 (At5PTase9) thought to be involved in cellular responses to abiotic stress (At2g01900 gene product). On the medium with phytate, several unique secreted proteins were also identified: kinase-interacting NET1A and NET1D proteins (At3g22790 and At1g03080 gene products), an allene oxide synthase involved in jasmonic acid signal pathway (At5g42650 gene product), a 


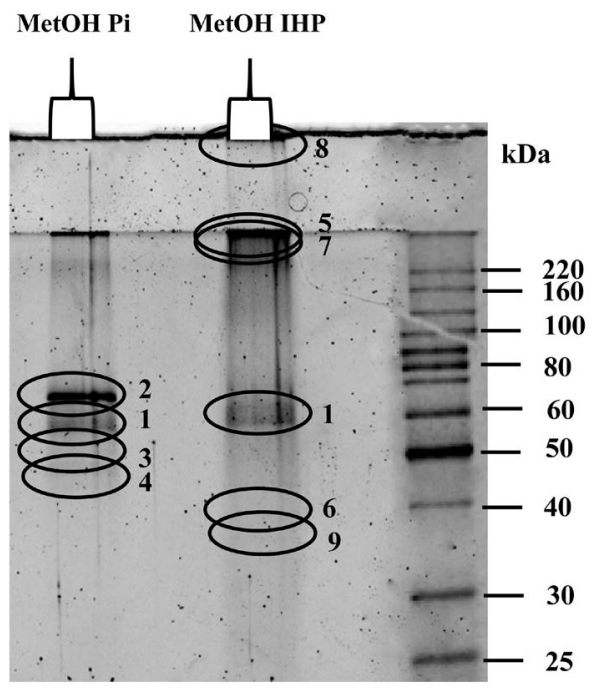

Figure 1. SDS/PAGE of proteins extracted with methanol. Identified and analyzed protein bands are indicated by black ovals. 1-At5g13610/ Q9FNB2, 2-At1g03400.1/ Q94A78, 3-At5g66260/Q9FH62, 4-At2g01900/Q9SIS4, 5-At3g22790/Q9LUI2, 6AT1g03080/F4HZB5, 7-At5g42650/Q96242, 8-At3g28600/F4J0C0, 9-At1g49180/ F4I1N8.

Table 1. Gene products secreted by Mt-0 ecotype in P-rich (Pi) and P-limiting (IHP) growth conditions.

\begin{tabular}{|c|c|c|c|c|}
\hline No. & $\begin{array}{l}\text { Gene/Protein } \\
\text { Accession }\end{array}$ & Annotation & P source & $\begin{array}{l}\text { Additional } \\
\text { References }\end{array}$ \\
\hline 1 & At5g13610/Q9FNB2 & $\begin{array}{l}\text { Retarded root growth - like protein, DUF155 domain-containing protein. } \\
\text { It has mitochondrion organization, located in cytoplasm and is involved in } \\
\text { abscisic acid-activated and mitochondria-nucleus signaling pathways. } \\
\text { Required for cell division in the root meristem. }\end{array}$ & $\mathrm{Pi}, \mathrm{IHP}$ & [22] \\
\hline 2 & At1g03400.1/Q94A78 & $\begin{array}{l}\text { 1-aminocyclopropane-1-carboxylate oxydase (ACO), involved in the last step of } \\
\text { ethylene biosynthesis as a catalyzer. Regulates glucosinolate biosynthetic processes. } \\
\text { Located in cytosol and cell membrane. }\end{array}$ & $\mathrm{Pi}$ & [23] \\
\hline 3 & At5g66260/Q9FH62 & $\begin{array}{l}\text { SAUR-like auxin-responsive protein family. Involved in response to } \\
\text { auxin and localized in the mitochondria. }\end{array}$ & $\mathrm{Pi}$ & [24] \\
\hline 4 & At2g01900/Q9SIS4 & $\begin{array}{l}\text { Type IV inositol polyphosphate 5-phosphatase } 9 \text { (At5PTase9). Response to } \\
\text { cellular salt stress, regulate the clathrin-dependent endocytosis and reactive } \\
\text { oxygen species metabolic processes. Has hydrolase activity and is involved in } \\
\text { phosphatidylinositol dephosphorylation. Regulates plant adaptations to } \\
\text { abiotic stress. Expressed especially in roots. }\end{array}$ & $\mathrm{Pi}$ & [25] \\
\hline 5 & At3g22790/Q9LUI2 & Protein NETWORKED 1A (NET1A). Involved in filamentous actin binding. & IHP & [25] \\
\hline 6 & AT1g03080/F4HZB5 & $\begin{array}{l}\text { Protein NETWORKED 1D (NET1D). Kinase interacting family protein, } \\
\text { localized in plasma membrane. Functions as actin filament binding protein. }\end{array}$ & IHP & [26] \\
\hline 7 & At5g42650/Q96242 & $\begin{array}{l}\text { Allene oxide synthase, chloroplastic (Cytochrome P450 74A, Hydroperoxidedehy- } \\
\text { drase). Involved in oxylipin biosynthesis as part of lipid metabolism. Regulates senes- } \\
\text { cence, pathogen defence, mechanotransduction and binding of iron ion, heme and } \\
\text { oxygen. Located in chloroplast and mitochondrial membranes. }\end{array}$ & IHP & [27] \\
\hline 8 & At3g28600/F4J0C0 & $\begin{array}{l}\text { AAA-type ATPase family protein, also known as nucleoside triphosphate } \\
\text { hydrolase superfamily protein. Located in plasma membrane and has } \\
\text { ATP-binding activity. Involved in response to salt stress. }\end{array}$ & IHP & [28] \\
\hline 9 & At1g49180/F4I1N8 & $\begin{array}{l}\text { Serine/threonine-protein kinase also known as autophagy-related protein } 1 \mathrm{t} \\
\text { (ATG1t). Involved in autophagy cascade mechanism, ATP and nucleic acid binding. } \\
\text { Subcellular location in autophagosome. }\end{array}$ & IHP & [29] \\
\hline
\end{tabular}


salt-stress responsive nucleoside triphosphate hydrolase involved in ATP binding (At3g28600 gene product) and a serine/threonine protein kinase (At1g49180 gene product) (Table 1 ).

Taken together, our data indicate that the presence or absence of easily extractable phosphorus has a significant effect on the composition of extracellular protein pools secreted by plant roots. Furthermore, our results suggest that the profiles of secreted proteins in $\mathrm{Pi}$ and phytate-containing growth conditions overlap only minimally, and most secreted proteins appear to be specific for growth on individual phosphorus source. While gene annotations indicate that at least some of the identified proteins may indeed have a role in phosphorus metabolism (i.e. Type IV inositol polyphosphate 5-phosphatase, nucleoside triphosphate hydrolase), the exact functions of each polypeptide in phosphorus acquisition needs to be analyzed further.

\subsection{Diversity of Organic Acids Secreted by Roots of $A$. thaliana Ecotypes Grown on Media with Different P Sources}

Plants are known to secrete a number of organic acids when grown in conditions of phosphorus deficiency. For example, canola roots secrete citric acid, while barley secretes malic acid, and potato roots secrete a number of organic acids [30]. To study the composition of organic acids secreted by $A$. thaliana roots, we extended our analysis to include three more ecotypes from different climatic zones: Col-0, Hi-0 and Sf-2. The Col-0 ecotype, originally from the plains of Central Europe, is the most commonly used ecotype for many ecological and molecular studies and represents a reference genome for $A$. thaliana. The Hi-0 ecotype (Hilversum, Netherlands) is characteristic of sandy and hilly regions of the Netherlands and grows among moorlands. Sf-2 ecotype (San Feliu, Spain) grows on the slopes of the Pyrenees Mountains down to the Mediterranean coast and is presumably adapted to both the highland conditions and wet climate of western Mediterranean.

Ecotype Hi-0 secreted tartrate under all conditions (Pi, ATP, IHP, noP) (Table 2). In addition, Hi-0 also produced succinate and oxalate, but only in the absence of any source of phosphorus in the medium (noP condition), suggesting that these organic acids are secreted in response to severe $\mathrm{P}$ limitation. Plants of Col-0 ecotype grown on the Pi medium secreted tartrate, oxalate and citrate (Table 2). When this ecotype was grown on ATP as the only source of phosphorus, plants secreted succinate and oxalate. Interestingly, succinate appears to be secreted by both Hi-o and Col-0ecotypes, but only in stress conditions (noP for Hi-0 and ATP for Col-0).

To further test the hypothesis that succinate and, possibly, oxalate, are stress related, we analyzed organic acid secretion by two other ecotypes, Mt- 0 and Sf- 2 . Secretion of succinate and oxalate in Mt- 0 and Sf- 2 ecotypes was observed during growth on several tested media, including Pi medium (Table 2). However, citrate was secreted only by the Mt-0 ecotype growing on the medium with ATP. Furthermore, tartrate was also secreted on Pi medium, suggesting that this 
Table 2. The diversity of organic acids secreted by $A$. thalianaroots (Nd-Not Determined).

\begin{tabular}{|c|c|c|c|c|c|c|c|}
\hline Ecotype & $\begin{array}{c}\text { Source of } \\
\text { phosphorus }\end{array}$ & Tartrate & Fumarate & Succinate & Oxalate & Malate & Citrate \\
\hline \multirow{4}{*}{$\mathrm{Hi}-0$} & $\mathrm{Pi}$ & + & - & - & - & - & - \\
\hline & noP & + & - & + & + & - & - \\
\hline & ATP & + & - & - & - & - & - \\
\hline & IHP & + & - & - & - & - & - \\
\hline \multirow{4}{*}{ Col-0 } & $\mathrm{Pi}$ & + & - & - & + & - & + \\
\hline & noP & nd & nd & nd & nd & nd & nd \\
\hline & ATP & - & - & + & + & - & - \\
\hline & IHP & nd & nd & nd & nd & nd & nd \\
\hline \multirow{4}{*}{ Mt-0 } & $\mathrm{Pi}$ & + & - & + & + & - & - \\
\hline & noP & nd & nd & nd & nd & nd & nd \\
\hline & ATP & - & - & + & - & - & + \\
\hline & IHP & - & - & - & + & - & - \\
\hline \multirow{4}{*}{ Sf-2 } & $\mathrm{Pi}$ & + & - & + & + & - & - \\
\hline & noP & nd & nd & nd & nd & nd & nd \\
\hline & ATP & nd & nd & nd & nd & nd & nd \\
\hline & IHP & - & - & + & + & - & - \\
\hline
\end{tabular}

organic acid is typically secreted under growth conditions with abundant $\mathrm{P}$ sources. Taken together, while no single organic acid can be pinpointed as a specific metabolite unique to stress conditions, our data indicate that secretion of some organic acids appears to be largely ecotype-specific (i.e. citrate for Col-0 and $\mathrm{Mt}-0$ ), while others are secreted uniformly by several natural populations (i.e. tartrate, succinate and oxalate). Furthermore, several tested organic acids (i.e. fumarate, malate) were not identified for any of the ecotypes used in this study. These data are in contrast to several previously published studies showing that $\mathrm{P}$ deficiency in radish promotes malate and succinate synthesis [31] while in $A$. thaliana rapidly inhibits root growth by activating the malate channel ALUMINUM-ACTIVATED MALATE TRANSPORTER1 [32], indicating that secretion of organic acids can change depending on specific growth conditions and on plant genotypes. Overall, whether secretion of a particular organic acid represents an adaptation factor remains to be further investigated.

\subsection{Plant Metabolites Excreted by A. thaliana Roots Growing on Various Sources of Phosphorus}

In addition to proteins and organic acids, plant roots secrete many other metabolites to the rhizosphere. We analyzed metabolites secreted by two Arabidopsis ecotypes, Col-0 and Hi-0, which were grown on medium containing inorganic 
phosphorus ( $\mathrm{Pi}$ ), medium without any sources of phosphorus (noP) and two types of organic phosphorus (ATP and IHP) (Figure 2). Analysis of excreted metabolites was performed by UHPLC-ESI-Q-TOF-MS/MS, and metabolite identification was performed using the RIKEN MSn spectral database for phytochemicals (ReSpect) http://spectra.psc.riken.jp/menta.cgi/respect/index [33].

Both Col-0 and Hi-0 ecotypes secreted a compound with retention time (RT) $23.7 \mathrm{~min}(\mathrm{~m} / \mathrm{z} 281.2792)$ (Figure 2(a) and Figure 2(b)). This compound corresponds to Oleic acid (molecular formula $\mathrm{C}_{18} \mathrm{H}_{34} \mathrm{O}_{2}$, Figure 3(a)). Interestingly, intracellular concentration of oleic acid in soybean seeds was previously shown to positively correlate with the amount of applied phosphorus fertilizers [34]. Oleic acid is also thought to modulate defense gene expression in Arabidopsis [35].

Additionally, Hi-0 ecotype excreted metabolites with RT of $18.5 \mathrm{~min}(\mathrm{~m} / \mathrm{z}$ 386.1803 and 408.1623 ) (Figure $2(\mathrm{a})$ ). The $\mathrm{m} / \mathrm{z} 386.1803$ peak was identified as 2'-Deoxycytidine-5'-diphosphate sodium salt (molecular formula $\mathrm{C}_{9} \mathrm{H}_{15} \mathrm{~N}_{3} \mathrm{O}_{10} \mathrm{P}_{2}$ ) (Figure 3(b)), while the $\mathrm{m} / \mathrm{z} 408.1623$ peak corresponds to tannin (molecular formula $\mathrm{C}_{23} \mathrm{H}_{22} \mathrm{~N}_{4} \mathrm{NaO}_{2}$ ) (Figure $3(\mathrm{c})$ ). Deoxycytidine participates in flowering induction and adaptation to environmental stress [36]. Various modifications of the cytidine base are also involved in plant epigenetic regulations. Current evidence indicates that deoxycytidine likely forms by the action of reactive oxygen species [36] and is located inside plant cells. However, our data indicate it can also be present in exudates.

Interestingly, we observed a higher peak for tannin in samples grown in conditions of phosphorus deficiency (noP, IHP). Tannins represent one of the most common and important groups of secondary metabolites in plants, and has previously been associated with plant defense mechanisms in case of biotic stress [37]. Enhanced synthesis of phenolic compounds, including tannins, has also been observed in Pinus silvestris under phosphorus deficiencies [38]. Overall, our data indicate that $A$. thaliana ecotypes differ in their physiological response to the source of phosphorus in the growth medium and respond by secreting different polypeptides, organic acids and secondary metabolites.

\section{Discussion and Conclusion}

Our data provide further confirmation to the notion that Arabidopsis ecotypes respond differently to variations in the phosphorus compounds present in the growth medium. Specifically, in response to phosphorus limitation plants secrete a number of proteins, organic acids and secondary metabolites. The spectrum of proteins and metabolites in the root secretome is further modulated by both specific phosphorus compounds in the medium (organic ATP and phytate versus inorganic Pi versus no phosphorus at all) and the nature of Arabidopsis ecotypes. In the future, it would also be interesting to analyze the spectrum of secreted proteins and metabolites in response to different concentrations of each $\mathrm{P}$ source. 

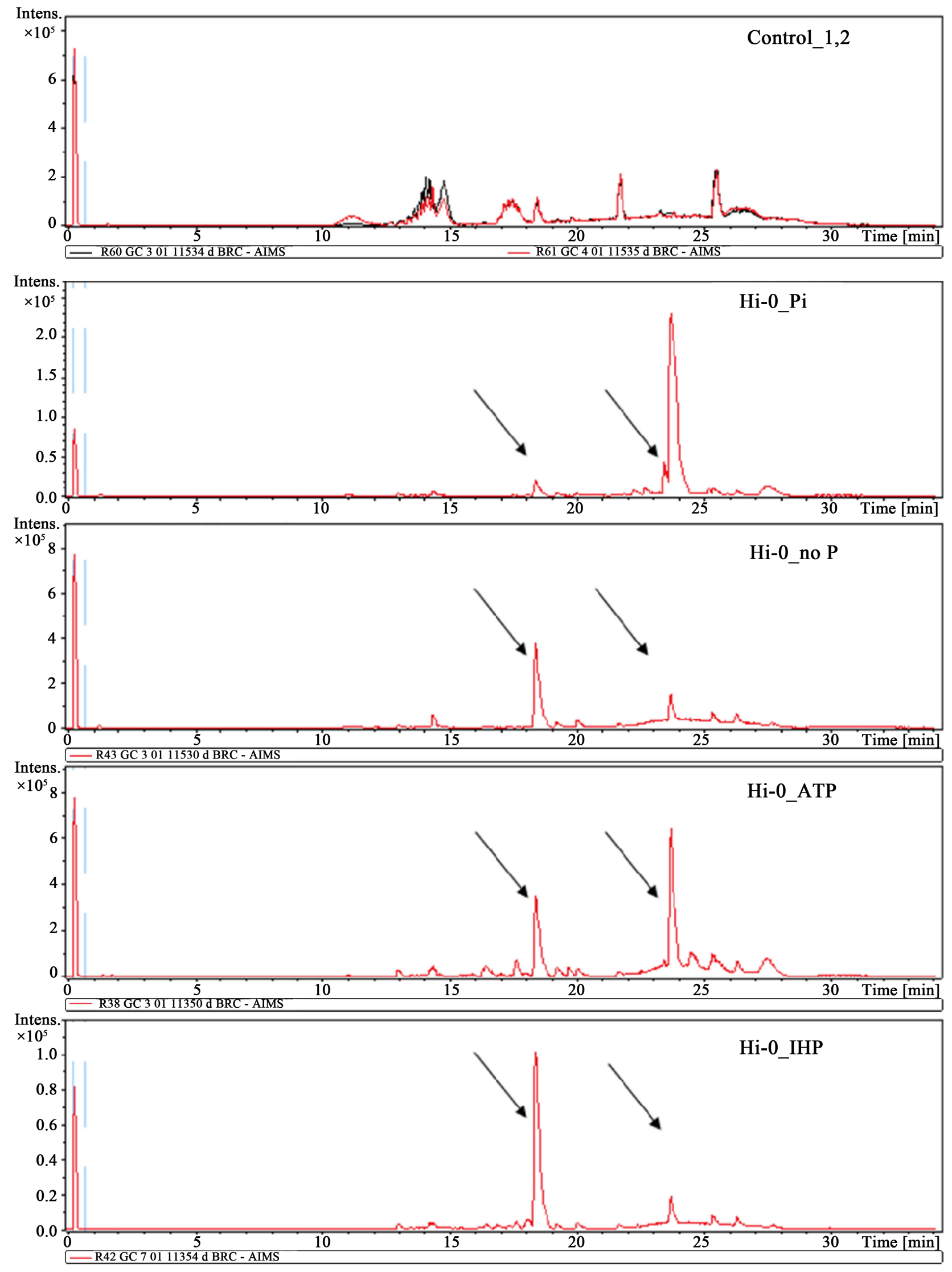

(a) 


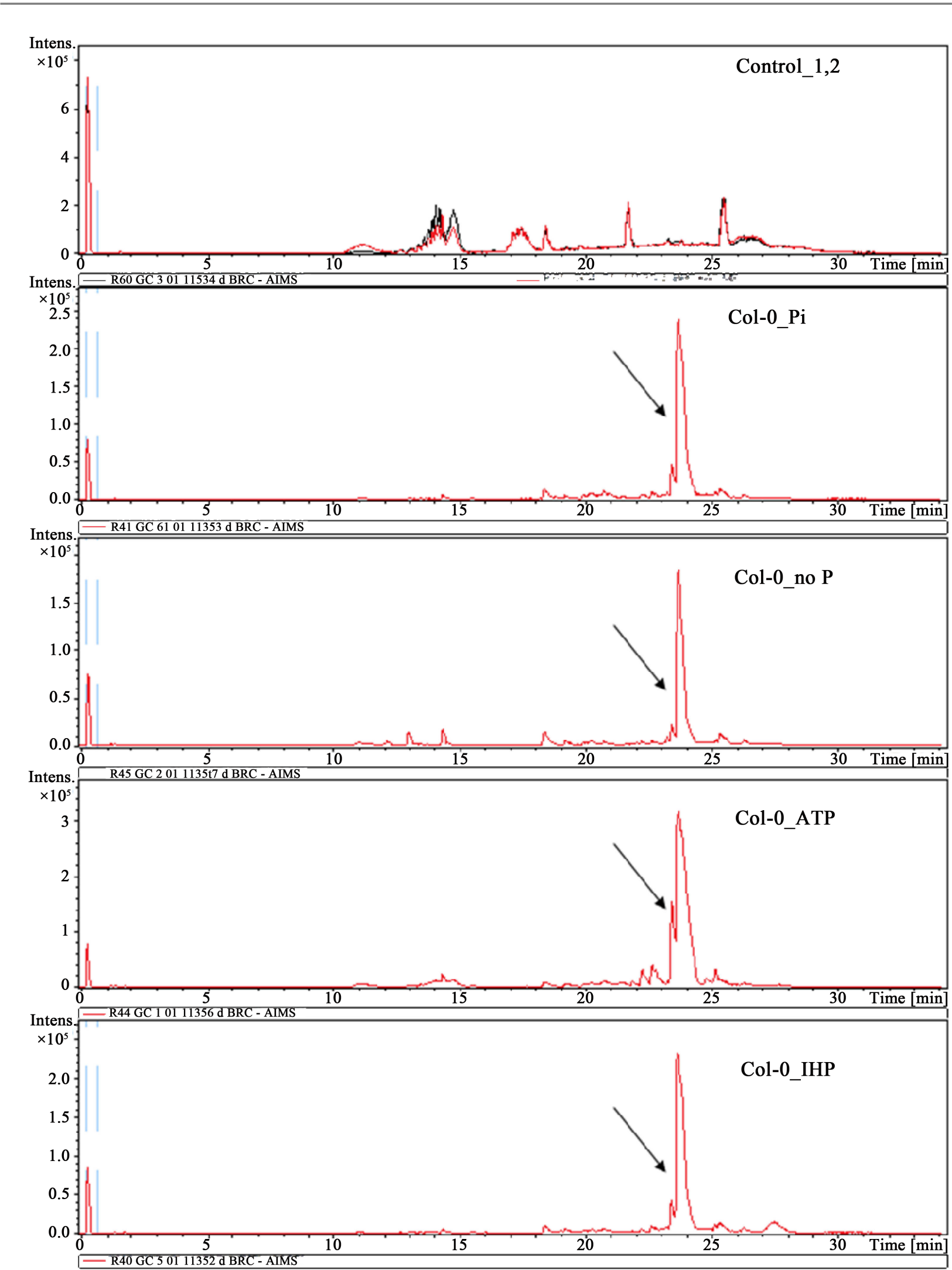

(b)

Figure 2. LC-MS chromatograms of metabolites excreted by roots of the $A$. thaliana Hi-0 (a) and Col-0 (b) ecotypes grown on different sources of phosphorus. Arrows indicate identified metabolites. 


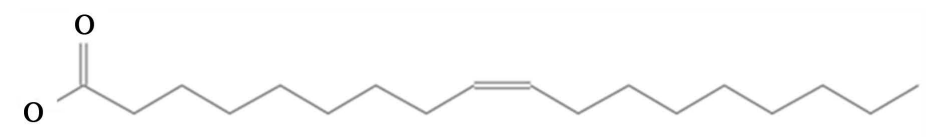

(a)

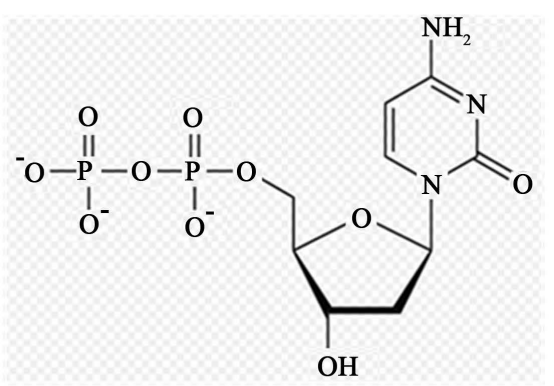

(b)

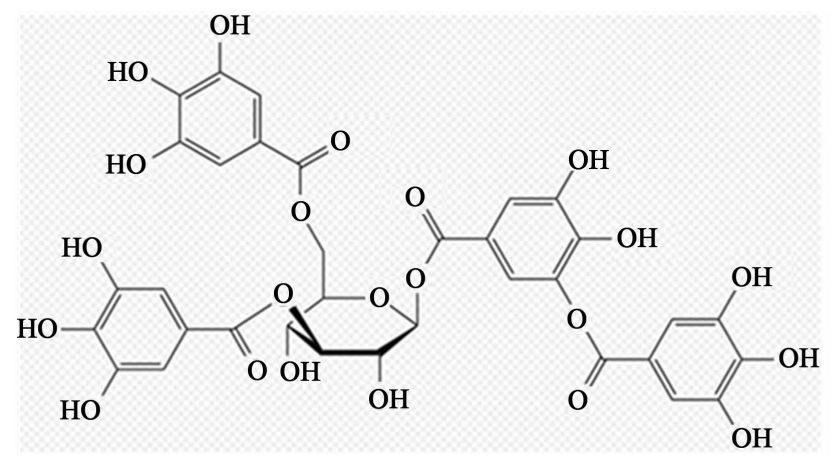

(c)

Figure 3. Molecular formulas of several selected metabolites excreted by $A$. thaliana roots. (a) Oleic acid; (b) 2'-Deoxycytidine-5'-diphosphate sodium salt; (c) Tannin.

\section{Acknowledgements}

This work was supported by the RFBR grants 18-34-00629, 16-34-60200, 15-0401645A, 18-016-00146 and the Russian Federal Program of Competitive Growth of Kazan Federal University. The authors are grateful to the Interdisciplinary Center for Collective Use at Kazan Federal University (ID RFMEFI59414X0003) sponsored by the Ministry of Education and Science of the Russian Federation. Dr. I.V. Khilyas was supported by the scholarship of the President of the Russian Federation for young scientists and graduate students. This work was supported by DAAD program "Yevgeny Zavoisky". The authors thank Prof. Dr. Gunter Lochnit, Laboratory of Protein Analytics, Department of Biochemistry, Justus-Liebig University, Giessen, Germany, for help with proteomic analysis.

\section{Conflicts of Interest}

The authors declare no competing interests.

\section{References}

[1] Hanif, M.K., Hameed, S., Imran, A., Naqqash, T., Shahid, M. and Van Elsas, J.D. (2015) Isolation and Characterization of a $\beta$-Propeller Gene Containing Phospho- 
bacterium Bacillus subtilis Strain KPS-11 for Growth Promotion of Potato (Solanum tuberosum L.). Frontiers in Microbiology, 6, 583. https://doi.org/10.3389/fmicb.2015.00583

[2] Yuan, H. and Liu, D. (2008) Signaling Components Involved in Plant Responses to Phosphate Starvation. Journal of Integrative Plant Biology, 50, 849-859. https://doi.org/10.1111/j.1744-7909.2008.00709.x

[3] Miller, S.S., Liu, J., Allan, D.L., Menzhuber, C., Federova, M. and Vance, C.P. (2001) Molecular Control of Acid Phosphatase Secretion into the Rhizosphere of Proteoid Roots. Plant Physiology, 127, 594-606. https://doi.org/10.1104/pp.010097

[4] Bozzo, G.G., Raghothama, K.G. and Plaxton, W.C. (2002) Purification and Characterization of Two Secreted Purple Acid Phosphatase Isozymes from PhosphateStarved Tomato (Lycopersicon esculentum) Cell Cultures. European Journal of Biochemistry, 269, 6278-6286. https://doi.org/10.1046/j.1432-1033.2002.03347.x

[5] Liang, C., Tian, J., Lam, H.M., Lim, B.L., Yan, X. and Liao, H. (2010) Biochemical and Molecular Characterization of PvPAP3, a Novel Purple Acid Phosphatase Isolated from Common Bean Enhancing Extracellular ATP Utilization. Plant Physiology, 152, 854-865. https://doi.org/10.1104/pp.109.147918

[6] Lung, S.-C., Leung, A., Kuang, R., Wang, Y., Leung, P. and Lim, B.-L. (2008) Phytase Activity in Tobacco (Nicotiana tabacum) Root Exudates Is Exhibited by a Purple Acid Phosphatase. Phytochemistry, 69, 365-373. https://doi.org/10.1016/j.phytochem.2007.06.036

[7] Tran, L.S., Nishiyama, R., Yamaguchi-Shinozaki, K. and Shinozaki, K. (2010) Potential Utilization of NAC Transcription Factors to Enhance Abiotic Stress Tolerance in Plants by Biotechnological Approach. GM Crops, 1, 32-39.

https://doi.org/10.4161/gmcr.1.1.10569

[8] Richardson, A.E., Barea, J.-M., McNeill, A.M. and Prigent-Combaret, C. (2009) Acquisition of Phosphorus and Nitrogen in the Rhizosphere and Plant Growth Promotion by Microorganisms. Plant Soil, 321, 305-339. https://doi.org/10.1007/s11104-009-9895-2

[9] Rugova, A., Puschenreiter, M., Santner, J., Fischer, L., Neubauer, S. and Koellensperger, G. (2014) Speciation Analysis of Orthophosphate and Myo-Inositol Hexakisphosphate in Soil- and Plant-Related Samples by Highperformance Ion Chromatography Combined with Inductively Coupled Plasma Mass Spectrometry. Jour nal of Separation Science, 37, 1711-1719. https://doi.org/10.1002/jssc.201400026

[10] Xiao, K., Katagi, H., Harrison, M. and Wang, Z.Y. (2006) Improved Phosphorus Acquisition and Biomass Production in Arabidopsis by Transgenic Expression of a Purple Acid Phosphatase Gene from M. truncatula. Plant Science, 170, 191-202. https://doi.org/10.1016/j.plantsci.2005.08.001

[11] Ma, X.F., Wright, E., Ge, Y., Bell, J., Xi, Y., Bouton, J.H. and Wang, Z.Y. (2009) Improving Phosphorus Acquisition of White Clover (Trifolium repens L.) by Transgenic Expression of Plant-Derived Phytase and Acid Phosphatase Genes. Plant Science, 176, 479-488. https://doi.org/10.1016/j.plantsci.2009.01.001

[12] Wang, X., Wang, Y., Tian, J., Lim, B.L., Yan, X. and Liao, H. (2009) Overexpressing AtPAP15 Enhances Phosphorus Efficiency in Soybean. Plant Physiology, 151, 233-240. https://doi.org/10.1104/pp.109.138891

[13] Valeeva, L., Nyamsuren, Ch., Sharipova, M. and Shakirov, E. (2018) Plant Stimulates Arabidopsis thaliana Growth on Phytate. Frontiers in Plant Science, 9, 1-14. https://doi.org/10.3389/fpls.2018.00186

[14] George, T.S., Simpson, R.J., Hadobas, P.A. and Richardson, A.E. (2005) Expression 
of a Fungal Phytase Gene in Nicotiana tabacum Improves Phosphorus Nutrition in Plants Grown in Amended Soil. Plant Biotechnology Journal, 3, 129-140. https://doi.org/10.1111/j.1467-7652.2004.00116.x

[15] Mudge, S.R., Smith, F.W. and Richardson, A.E. (2003) Root Specific and Phosphate Regulated Expression of Phytase under the Control of a Phosphate Transporter Promoter Enables Arabidopsis to Grow on Phytate as a Sole P Source. Plant Science, 165, 871-878. https://doi.org/10.1016/S0168-9452(03)00286-3

[16] Murashige, T. and Skoog, F. (1962) A Revised Medium for Rapid Growth and Bio-Assays with Tobacco Tissue Cultures. Physiologia Plantarum, 15, 473-497. https://doi.org/10.1111/j.1399-3054.1962.tb08052.x

[17] Tocquin, P., Corbesier, L., Havelange, A., Pieltain, A., Kurtem, E., Bernier, G. and Perilleux, C. (2003) A Novel High Efficiency, Low Maintenance, Hydroponic System for Synchronous Growth and Flowering of Arabidopsis thaliana. BMC Plant Biology, 3, 1-10. https://doi.org/10.1186/1471-2229-3-2

[18] Dundek, P., Holik, L., Rohlik, T., Hromadko, L., Vranova, V., Rejchek, K. and Formanek, P. (2011) Methods of Plant Root Exudates Analysis: A Review. Acta Universitatis Agriculturae et Silviculturae Mendelianae Brunensis, 3, 241-246. https://doi.org/10.11118/actaun201159030241

[19] Song, L., Jenner, M., Masschelein, J., Jones, C., Bull, M.J., Harris, S.R., Hartkoorn, R.C., Vocat, A., Romero-Canelon, I., Coupland, P., Webster, G., Dunn, M., Weiser, R., Paisey, C., Cole, S.T., Parkhill, J., Mahenthiralingam, E. and Challis, G.L. (2017) Discovery and Biosynthesis of Gladiolin: A Burkholderia gladioli Antibiotic with Promising Activity against Mycobacterium tuberculosis. Journal of the American Chemical Society, 139, 7974-7981. https://doi.org/10.1021/jacs.7b03382

[20] Lee, H.S. (1993) HPLC Method for Separation and Determination of Nonvolatile Organic Acids in Orange Juice. Journal of Agricultural and Food Chemistry, 41, 1991-1993. https://doi.org/10.1021/jf00035a033

[21] Basu, U., Francis, J.L., Whittal, R.M., Stephens, J.L., Wang, Y., Zaiane, O.R., Goebel, R., Muench, D.G., Good, A.G. and Taylor, G.J. (2006) Extracellular Proteomes of Arabidopsis thaliana and Brassica napus Roots: Analysis and Comparison by MudPIT and LCMS/MS. Plant Soil, 286, 357-376. https://doi.org/10.1007/s11104-006-9048-9

[22] Yao, X., Li, J., Liu, J. and Liu, K. (2015) An Arabidopsis Mitochondria-Localized RRL Protein Mediates Abscisic Acid Signal Transduction through Mitochondrial Retrograde Regulation Involving ABI4. Journal of Experimental Botany, 66, 64316445. https://doi.org/10.1093/jxb/erv356

[23] Veyres, N., Danon, A., Aono, M., Galliot, S., Karibasappa, Y.B., Diet, A., Grandmottet, F., Tamaoki, M., Lesur, D., Pilard, S., Boitel-Conti, M., Sangwan-Norreel, B.S. and Sangwan, R.S. (2008) The Arabidopsis Sweetie Mutant Is Affected in Carbohydrate Metabolism and Defective in the Control of Growth, Development and Senescence. The Plant Journal, 55, 665-686. https://doi.org/10.1111/j.1365-313X.2008.03541.x

[24] https://www.arabidopsis.org

[25] Golani, Y., Kayea, Y., Gilhara, O., Ercetinb, M., Gillaspyb, G. and Levinea, A. (2013) Inositol Polyphosphate Phosphatidylinositol 5-Phosphatase9 (At5PTase9) Controls Plant Salt Tolerance by Regulating Endocytosis. Molecular Plant, 6, 1781-1794. https://doi.org/10.1093/mp/sst072

[26] Deeks, M.J., Calcutt, J.R., Ingle, E.K.S., Hawkins, T.J., Chapman, S., Richardson, A.C., Mentlak, D.A., Dixon, M.R., Cartwright, F., Smertenko, A.P., Oparka, K. and 
Hussey, P.J. (2012) A Superfamily of Actin-Binding Proteins at the Actin-Membrane Nexus of Higher Plants. Current Biology, 22, 1595-1600. https://doi.org/10.1016/j.cub.2012.06.041

[27] Laudert, D., Pfannschmidt, U., Lottspeich, F., Hollnder-Czytko, H. and Weiler, E.W. (1996) Cloning, Molecular and Functional Characterization of Arabidopsis thaliana Allene Oxide Synthase (CYP 74), the First Enzyme of the Octadecanoid Pathway to Jasmonates. Plant Molecular Biology, 31, 323-335. https://doi.org/10.1007/BF00021793

[28] Ma, S., Gong, Q. and Bohnert, H.J. (2006) Dissecting Salt Stress Pathways. Journal of Experimental Botany, 57, 1097-1107. https://doi.org/10.1093/jxb/erj098

[29] Suttangkakul, A., Li, F., Chung, T. and Vierstra, R.D. (2011) The ATG1/ATG13 Protein Kinase Complex Is Both a Regulator and a Target of Autophagic Recycling in Arabidopsis. The Plant Cell Preview, 10, 3761-3779. https://doi.org/10.1105/tpc.111.090993

[30] Wang, Y.-L., Almvik, M., Clarke, N., Eich-Greatorex, S., Ogaard, A.F., Krogstad, T., Lambers, H. and Clarke, J.L. (2015) Contrasting Responses of Root Morphology and Rootexuded Organic Acids to Low Phosphorus Availability in Three Important Food Crops with Divergent Root Traits. AoB Plants, 7, plv097. https://doi.org/10.1093/aobpla/plv097

[31] Zhang, F.S., Ma, J. and Cao, Y.P. (1997) Phosphorus Deficiency Enhances Root Exudation of Low-Molecular Weight Organic Acids and Utilization of Sparingly Soluble Inorganic Phosphates by Radish (Raghanus satiuvs L.) and Rape (Brassica napus L.) Plants. Plant and Soil, 196, 261-264. https://doi.org/10.1007/978-94-009-0047-9_88

[32] Balzergue, C., Dartevelle, T., Godon, C., Laugier, E., Meisrimler, C., Teulon, J.-M., Creff, A., Bissler, M., Brouchoud, C., Hagege, A., Muller, J., Chiarenza, S., Javot, H., Becuwe-Linka, N., David, P., Peret, B., Delannoy, E., Thibaud, M.-C., Armengaud, J., Abel, S., Pellequer, J.-L., Nussaume, L. and Desnos, T. (2017) Low Phosphate Activates STOP1-ALMT1 to Rapidly Inhibit Root Cell Elongation. Nature Communications, 8, Article No. 15300. https://doi.org/10.1038/ncomms15300

[33] Sakurai, T., Yamada, Y., Sawada, Y., Matsuda, F., Akiyama, K., Shinozaki, K., Hirai, M.Y. and Saito, K. (2013) PRIMe Update: Innovative Content for Plant Metabolomics and Integration of Gene Expression and Metabolite Accumulation. Plant and Cell Physiology, 54, 1-8. https://doi.org/10.1093/pcp/pcs184

[34] Yin, X., Bellaloui, N., McClure, A.M., Tyler, D.D. and Mengistu, A. (2016) Phosphorus Fertilization Differentially Influences Fatty Acids, Protein, and Oil in Soybean. American Journal of Plant Science, 7, 1975-1992. https://doi.org/10.4236/ajps.2016.714180

[35] Kachroo, A., Venugopal, S.C., Lapchyk, L., Falcone, D., Hildebrand, D. and Kachroo, P. (2004) Oleic Acid Levels Regulated by Glycerolipid Metabolism Modulate Defense Gene Expression in Arabidopsis. PNAS, 101, 5152-5157. https://doi.org/10.1073/pnas.0401315101

[36] Liu, S., Dunwell, T.L., Pfeifer, G.P., Dunwell, J.M., Ullah, I. and Wang, Y. (2013) Detection of Oxidation Products of 5-Methyl-2'-Deoxycytidine in Arabidopsis DNA. PLoS ONE, 8, e84620. https://doi.org/10.1371/journal.pone.0084620

[37] Hassanpour, S., Maherisis, N., Eshratkhah, B. and Baghbani Mehmandar, F. (2011) Plants and Secondary Metabolites (Tannins): A Review. International Journal of Forest, Soil and Erosion, 1, 47-53.

[38] Davies, R.I., Coulson, C.B. and Leisw, D.A. (1964) Polyphenols Is Plant, Humus, 
and Soil IV. Factors Leading to Increase in Biosynthesis of Polyphenol in Leaves and Their Relationship to Mull and More Formation. Journal of Soil Science, 15, 310. https://doi.org/10.1111/j.1365-2389.1964.tb02228.x 